\title{
Effect of Implant Platform Connection and Abutment Material on Removal Torque and Implant Hexagon Plastic Deformation
}

\author{
Paulo Henrique de Souza Pereira ${ }^{1}$ Marina Amaral ${ }^{1}$ Kusai Baroudi ${ }^{1} \quad$ Rafael Pino Vitti $^{1}$ \\ Mohammad Zakaria Nassani² Laís Regiane da Silva-Concílio ${ }^{1}$
}

1Department of Dentistry, University of Taubaté, Taubaté, Brazil
2Department of Prosthetic Dental Science, AlFarabi College of
Dentistry and Nursing, Riyadh, Saudi Arabia

\begin{abstract}
Address for correspondence Kusai Baroudi, Department of Dentistry, University of Taubaté, Rua dos Operários,09- Centro, Taubaté - SP, Brazil. CEP, 12020-330, (e-mail: d_kusai@yahoo.co.uk).
\end{abstract}

\begin{abstract}
Keywords

- internal hexagon implant

- zirconia abutment

- connection wear

Objectives The aim of this study was to evaluate the plastic deformation of the hexagonal connection, and the removal torque of the implant-abutment joint of two dental implants combined with internal or external hexagonal connection implants after mechanical cycling.

Materials and Methods Twenty-four dental implants were used in the study. Half of the implants had internal hexagonal connections (IH; Titamax II Plus) and the other half had external hexagonal connections (EH; Titamax Ti Ex). Four groups of two types of dental implant abutments (titanium: Ti, UCLA II Plus and zirconia: Zr, fabricated by CAD/CAM; $n=6$ ) were investigated. The abutments received a metallic crown and the settings were submitted to mechanical cycling (MC; $10^{6}$ cycles, axial load, $120 \mathrm{~N}$ ). The connection surface area was measured by scanning electron microscope (SEM) images. The removal torque was evaluated and the plastic deformation of the hexagonal surface of the implant was measured by comparing the images before and after MC.

Statistical Analysis Paired- $t$ test was used to analyze the data statistically at a significance level of $\alpha=0.05$.

Results The torque values decreased for all groups after MC, and the hexagonal surface area decreased due to plastic deformation for $\mathrm{IH}$ and $\mathrm{EH}$ associated with $\mathrm{Zr}$ abutments.

Conclusions Zirconia abutments showed the worst plastic deformation of the implant connection surface and torque loosening when associated with $\mathrm{IH}$ implant.
\end{abstract}

\section{Introduction}

The replacement of lost teeth by osseointegrated implants is an established therapy, with long-term reports of success. ${ }^{1,2}$ Titanium (Ti) was the first material to be applied in the fabrication of implants and abutments for the installation of prosthetic restoration. However, such material may present esthetic limitations when the thickness of peri-implant soft tissue is lower than $2 \mathrm{~mm}^{3}$

Esthetic abutments have been applied as an alternative to Ti abutments. ${ }^{4}$ Ceramics may be used for the fabrication of components and also solve the esthetic issue; however, function should be ensured, without compromising the bone-implant-restoration system. ${ }^{5}$ Some options for the fabrication of ceramic implant components are alumina and zirconia. ${ }^{6}$ Partially stabilized zirconia possesses high-mechanical strength and is a good alternative for Ti abutments in the maxillary anterior region. $^{\text {? }}$

However, the clinical behavior of zirconia as implant abutment is still controversial. Mechanical characteristics of zirconia ceramic, such as the hardness, ${ }^{8}$ are very different from those of the titanium..$^{9}$ Also, the elastic modulus of 
both materials is very different. ${ }^{10}$ This may lead to different behaviors in terms of bending and deformation when a load is applied to the system..$^{10}$ In this scenario, the implant-abutment joint may get compromised.

Literature reports significant difference in the wear of the hexagon surface of $\mathrm{Ti}$ implants when associated with $\mathrm{Zr}$ or $\mathrm{Ti}$ abutments. ${ }^{11,12}$ The wear of the connection may lead to loosening of the abutment screw torque, and is associated with loosening of the restoration as well as the dental implant. The wear of the implant-abutment joint may also cause misfit and a space in the subgingival zone, thus favoring bacterial microleakage and proliferation. ${ }^{4,5,13,14}$

The design of the implant connection may also influence the implant-abutment interface, since this is the area of higher stress concentration in the system. ${ }^{15-17}$ External connections $(\mathrm{EH})$ have the lowest torque loosening, when compared with the internal hexagonal connection (IH), ${ }^{18,19}$ and better stress distribution, since they present a higher contact area between the abutment and implant platforms than $\mathrm{IH} .^{20}$

Thus, the aim of this study was to evaluate the removal torque and plastic deformation of the hexagonal implant connection after mechanical cycling when $\mathrm{Zr}$ and $\mathrm{Ti}$ abutments are associated with Ti implants. The tested hypothesis was that $\mathrm{Zr}$ abutments would present greater hexagonal implant deformation, and lower values of removal torque than Ti abutments in both internal and external hexagonal implant connections.

\section{Materials and Methods}

The sample size calculation was performed using the Bioestat 5.0 software to offer results with 0.9 power and 0.05 significance. Calculation was based on data from previous literature, ${ }^{16}$ and resulted in $n=5$. Extra sample was added to each group, resulting in $n=6$. Samples were evaluated before and after mechanical cycling. Thus, the study was conducted using 24 dental implants $(n=6)(3.75 \times 13 \mathrm{~mm})$ with a 4.1 $\mathrm{mm}$ platform connection. Half of the implants had internal hexagonal connections (IH; Titamax II Plus, Neodent, Curitiba, PR, Brazil) and the other half had external hexagonal connections (EH; Titamax Ti Ex, Neodent, Curitiba, PR, Brazil).

The implants were embedded into epoxy resin (TCR-550/ XR-451; Triepox, Sao Paulo, SP, Brazil) with a parallel surveyor (B2; Bioart, Sao Carlos, SP, Brazil). The initial images of the hexagons from the implant connection were obtained using a scanning electron microscope (SEM; InspectF50, FEI, Hillsboro, Oregon, USA) with 70X magnification. The surface areas of the hexagons were measured with digital software (Image Proplus 6.0, Media Cybernetics, Rockville, MD, USA).

The prosthetic abutments were selected according to the implant connection, using two different materials: titanium (UCLA II Plus; Neodent, Curitiba, PR, Brazil) and zirconia (fabricated by CAD/CAM, Zirkonzahn System, Gays, Bolzano, Italy). The abutments were attached to the implants by titanium screws with a square head. The following four groups were considered: $\mathrm{IH} / \mathrm{Ti}, \mathrm{IH} / \mathrm{Zr}, \mathrm{EH} / \mathrm{Ti}$, and $\mathrm{EH} / \mathrm{Zr}$.

The Ti abutments were $10 \mathrm{~mm}$ high with an axial convergence of 30 degrees. The $\mathrm{Zr}$ abutments were fabricated from the scans of the Ti abutments and milled in CAD/CAM unity (Zirkonzahn System; Gays, Bolzano, Italy). The abutments were screwed on each implant with manual torque meter (BTG; Tohnichi, Buffalo Grove, IL, USA), as recommended by the manufacturer: $30 \mathrm{~N} . \mathrm{cm}$ (Ti abutments) and $20 \mathrm{~N} . \mathrm{cm}(\mathrm{Zr}$ abutments). The torque was checked and applied again after 10 minutes.

Subsequently, simplified metallic crowns were waxed on each abutment, $2 \mathrm{~mm}$ away from the implant-abutment joint, and fabricated into chrome-cobalt alloy (Degudent, Dentsply, York, PA, USA) by lost-wax casting process. The metallic crown was $8 \mathrm{~mm}$ high with a flat occlusal surface to avoid oblique loads during mechanical cycling, and had a hole in the central area for assessment of the abutment fixation screw and measurement of torque after mechanical cycling. The crown was cemented to the abutments with zinc-phosphate cement (SS-White, Sao Paulo, SP, Brazil).

Then, the samples were subjected to mechanical cycling (MC) in a universal testing machine (8801, INSTRON Fatigue Testing Systems, Norwood, MA, USA). The mechanical cycles $\left(10^{6}\right)$ were applied with $120 \mathrm{~N}$ axial load and $10 \mathrm{~Hz}$ frequency. The axial load was applied at the center of the metallic crown by a tungsten piston with a spherical tip (diameter: $4 \mathrm{~mm}$ ).

After MC, the removal torque was measured by removing the abutment screw with a manual torque meter. The surfaces of the implant hexagon were observed using a scanning electron microscope (SEM). The wear/plastic deformation of the surface of the implant hexagon was evaluated by calculating the difference between the measurement of the surface area of each hexagon before and after MC.

The obtained data were subjected to paired-t test at the significance level of $\alpha=0.05$. The factors were combined and tested for correlation.

\section{Results}

After MC, small fractures at the margins of the $\mathrm{Zr}$ abutments were observed. Regarding the values of the removal torque of abutments, all groups showed a decrease in the values after MC ( - Table 1). This decrease was statistically significant different $(p<0.05)$. IH/Zr showed significant decrease in removal torque compared with the other groups. Two $\mathrm{Zr}$ abutments associated to internal hexagon implants presented transversal fractures.

After the removal of the abutment/crown, all groups showed statistically significant decrease in the implant hexagon surface area $(p<0.05)$ except for the $\mathrm{IH} / \mathrm{Ti}$ group $(p>0.05)$. The greatest decrease in the implant hexagon surface area was observed for $\mathrm{IH} / \mathrm{Zr}$ (-Table 2). - Fig. 1 shows a SEM image (60X magnification) of the implant hexagon surface from one representative sample of each tested group, before and after MC. After MC, it is possible to observe rounding of hexagon corners and deformation of the hexagon edges.

There was no correlation (Pearson's correlation test) between the results of the reversal torque and plastic deformation $(p=0.118)$. 


\section{Discussion}

The present study showed that the $\mathrm{Zr}$ abutments had the lowest reverse torque values when associated with IH implants, accepting the proposed hypotheses. The decrease in removal torque after MC was significant in all the groups tested. The possible causes for torque loosening in all the groups may be the occurrence of micromovements between the involved components when a load was applied at the metallic crown. The initial torque promotes friction between the interfaces of the abutment, screw, and implant platform. When micromovements are present due to the loading of the metallic crown during MC, there is wear of these interfaces, and the retention of the screw may decrease. ${ }^{21}$

The greatest torque decrease was recorded for $\mathrm{IH} / \mathrm{Zr}$. The differences in hardness and elastic modulus of $\mathrm{Zn}$ and $\mathrm{Ti}$ may lead to unequal stress distribution at the interface of components during load application, with plastic deformation of the Ti screw (lowest hardness) and loss of abutment torque. ${ }^{15}$

The group that had $\mathrm{Zr}$ abutment associated with $\mathrm{IH}$ showed $40 \%$ decrease in the removal torque values. Besides the effect of the material discussed above, the IH abutment was slightly longer than the abutment for $\mathrm{EH}$, considering the portion that was attached to the internal hexagon inside the implant. It was already reported that a greater height of the abutment was related to a decrease in the reverse torque values due to changes in force moment. ${ }^{11}$ The moment formed by high abutments increased the stress from MC at the screw (lever fulcrum), leading to wear, torque loss, and/or fracture of the abutment. Two Zr abutments associated with IH exhibited transverse fractures after reverse torque application. In the study of Fabbri et al, 2017, they found that $\mathrm{Zr}$ abutments associated with IH implants had the highest fracture incidence after 6 years of clinical follow-up. ${ }^{22}$ Considering the internal part, high and thin abutments were more prone to fracture and torque loss when compared with large and short abutments. ${ }^{23} \mathrm{EH}$ implants associated with Ti abutments were the only group that did not exhibit a decrease in the torque values after MC.

The decrease in the hexagonal surface after MC was significant for EH implants, with both $\mathrm{Ti}$ and $\mathrm{Zr}$ abutments
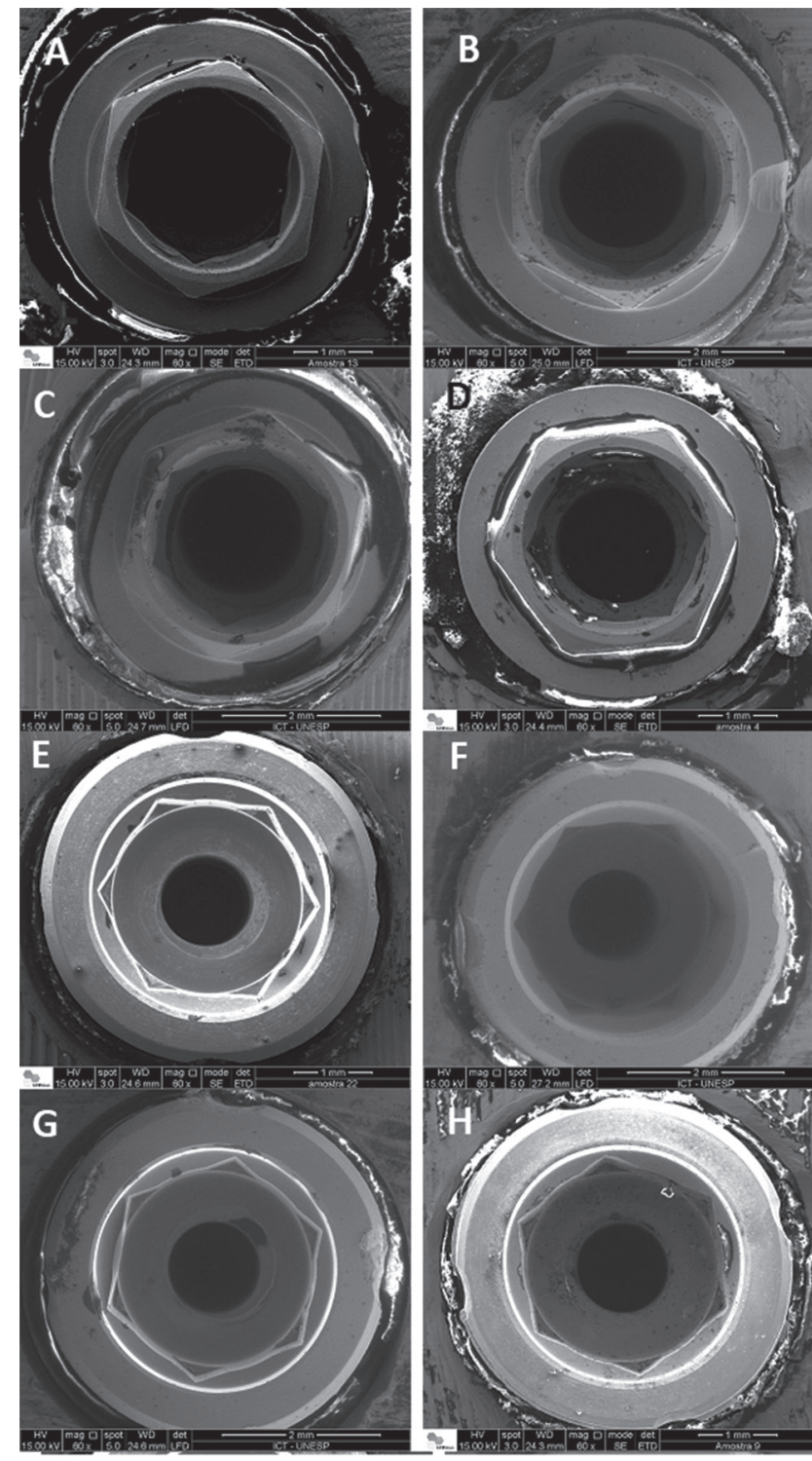

Fig. 1 SEM images of the implant hexagon surface of one sample from each group. (A) EH/Zr before mechanical cycling, (B) EH/Zr after mechanical cycling, (C) EH/Ti before mechanical cycling, (D) EH/Ti after mechanical cycling, (E) $\mathrm{IH} / \mathrm{Zr}$ before mechanical cycling, (F) $\mathrm{IH} /$ $\mathrm{Zr}$ after mechanical cycling, (G) IH/Ti before mechanical cycling, $(\mathrm{H})$ $\mathrm{IH} / \mathrm{Ti}$ after mechanical cycling. SEM, scanning electron microscope.

Table 1 Reverse torque values of each group

\begin{tabular}{|l|l|l|l|l|}
\hline Groups tested & Initial torque $(\mathbf{N} . c m)$ & $\begin{array}{l}\text { Reverse torque (N.cm) after mechanical } \\
\text { cycling }\end{array}$ & \% of torque loosening & $p$-Value \\
\hline $\mathrm{EH} / \mathrm{Zr}$ & 20.00 & $17.33(2.27)$ & 13.3 & 0.035 \\
\hline $\mathrm{EH} / \mathrm{Ti}$ & 32.00 & $29.83(1.29)$ & 6.8 & 0.009 \\
\hline $\mathrm{IH} / \mathrm{Zr}$ & 20.00 & $12.00(2.25)$ & 40.0 & 0.000 \\
\hline $\mathrm{IH} / \mathrm{Ti}$ & 32.00 & $27.58(1.53)$ & 13.8 & 0.001 \\
\hline
\end{tabular}

Table 2 Area of implant hexagon surfaces before and after mechanical cycling (MC)

\begin{tabular}{|l|l|l|l|l|}
\hline Groups tested & Before $\mathrm{MC}\left(\mathrm{mm}^{2}\right)$ & After $\mathrm{MC}\left(\mathrm{mm}^{2}\right)$ & \% of decrease in area & $p$-Value \\
\hline $\mathrm{EH} / \mathrm{Zr}$ & $73.66(3.21)$ & $69.44(2.56)$ & 5.7 & 0.037 \\
\hline $\mathrm{EH} / \mathrm{Ti}$ & $73.41(2.99)$ & $69.33(2.10)$ & 5.5 & 0.013 \\
\hline $\mathrm{IH} / \mathrm{Zr}$ & $129.2(8.34)$ & $116.97(1.16)$ & 9.5 & 0.014 \\
\hline $\mathrm{IH} / \mathrm{Ti}$ & $118.4(6.95) \mathrm{A}$ & $115.1(3.69)$ & 2.7 & 0.077 \\
\hline
\end{tabular}


(-Fig. 1A-D); however, hexagons associated with $\mathrm{Zr}$ abutments had the greatest decrease in area. Besides the implications of combination between $\mathrm{Ti}$ and $\mathrm{Zr}$ mentioned above, the material with lower elastic modulus, Ti in this case, tended to suffer deformation when stresses were concentrated at the interface of both materials. Alterations at implant abutment joint are reported to be related to the shape of the milled abutment hexagon. ${ }^{24}$ The plastic deformation of connection hexagons (-Fig. 1B, 1D, 1H) may lead to loss of retention of the screw and thus create a misfit between the abutment and implant platform, leading to clinical failure..$^{25,26}$

The region of the implant-Zr abutment connection was reported as the weakest part in internal connections. ${ }^{27}$ Torque (20 N.cm) was applied, as recommended by the manufacturer and as already tested in other studies ${ }^{28}$; however, torque application in cases of nonpassive fit might have created cracks at the cervical regions of the $\mathrm{Zr}$ abutments, ${ }^{13}$ which were propagated during $\mathrm{MC}$, thereby resulting in the fracture of two abutments. The loss of specimens, manufactured with one-piece zirconia abutments during chewing simulation, was already reported in literature and they also present lower fracture loads than noncycled specimens. ${ }^{29}$ Titanium abutments present 30 to $40 \%$ higher strength than zirconia abutment, limiting the indication of the ceramic abutment to regions of low-chewing forces (anterior region). ${ }^{30}$

Besides that, the higher space between abutment and implant may have contributed to the micromovements in the implant abutment joint during $\mathrm{MC}$, resulting in torque loosening and wear of implant connection when the $\mathrm{Zr}$ abutment was used. ${ }^{31}$

The present research evaluated only one commercial brand of implant and abutment, in addition to fabricated $\mathrm{Zr}$ abutments based on Ti abutments. Other implant-abutment assemblies and commercial brands, like other $\mathrm{Zr}$ abutment dimensions, may present different outcomes. Moreover, the use of titanium base in zirconia abutments may enhance the strength of these abutments. ${ }^{29}$

\section{Conclusions}

Within the limitations of the present research, negative results were observed for $\mathrm{Zr}$ abutments in terms of plastic deformation of implant connection surface. The association of internal hexagonal connection and zirconia abutment was the worst situation in terms of torque removal.

\section{Conflict of Interest}

None declared.

\section{Acknowledgments}

Authors thank Neodent (JJGC Ind \& Com. Of Dental Materials S.A.) for donating the materials for this research.

\section{References}

1 Ravald N, Dahlgren S, Teiwik A, Gröndahl K. Long-term evaluation of Astra Tech and Brånemark implants in patients treated with full-arch bridges. Results after 12-15 years. Clin Oral Implants Res 2013;24(10):1144-1151
2 Hanif A, Qureshi S, Sheikh Z, Rashid H. Complications in implant dentistry. Eur J Dent 2017;11(1):135-140

3 Sala L, Bascones-Martínez A, Carrillo-de-Albornoz A. Impact of abutment material on peri-implant soft tissue color. An in vitro study. Clin Oral Investig 2017;21(7):2221-2233

4 Silva NR, Thompson VP, Valverde GB, et al. Comparative reliability analyses of zirconium oxide and lithium dissilicate restorations in vitro and in vivo. J Am Dent Assoc 2011;142(Suppl):(2):4S-9S

5 Magne P, Magne M, Jovanovic SA. An esthetic solution for single-implant restorations - type III porcelain veneer bonded to a screw-retained custom abutment: a clinical report. J Prosthet Dent 2008;99(1):2-7

6 Gautam C, Joyner J, Gautam A, Rao J, Vajtai R.Zirconia based dental ceramics: structure, mechanical properties, biocompatibility and applications. Dalton Trans 2016;45(48):19194-19215

7 Sui X, Wei H, Wang D, et al. Experimental research on the relationship between fit accuracy and fracture resistance of zirconia abutments. J Dent 2014;42(10):1353-1359

8 Ban S. Reliability and properties of core materials for allceramic dental restorations. Jpn Dent Sci Rev 2008;44:3-21

9 Elias CN, Fernandes DJ, Resende CR, Roestel J. Mechanical properties, surface morphology and stability of a modified commercially pure high strength titanium alloy for dental implants. Dent Mater 2015;31(2):e1-e13

10 Chun KJ, Lee JY. Comparative study of mechanical properties of dental restorative materials and dental hard tissues in compressive loads. J Dent Biomech 2014;5;doi:10.1177/1758736014555246

11 Yüzügüllü B, Avci M. The implant-abutment interface of alumina and zirconia abutments. Clin Implant Dent Relat Res 2008;10(2):113-121

12 Stimmelmayr M, Sagerer S, Erdelt K, Beuer F. In vitro fatigue and fracture strength testing of one-piece zirconia implant abutments and zirconia implant abutments connected to titanium cores. Int J Oral Maxillofac Implants 2013;28(2): 488-493

13 Lopez-Suarez C, Gonzalo E, Pelaez J. Serrano B, Suarez MJ. Marginal vertical discrepancies of monolithic and veneered zirconia and metal-ceramic three-unit posterior fixed dental prostheses. Int J Prosthodont 2016;29(3):256-258

14 Prado AM, Pereira J, Silva FS, et al. Wear of Morse taper and external hexagon implant joints after abutment removal. J Mater Sci Mater Med 2017;28(5):65

15 Carvalho MA, Sotto-Maior BS, Del Bel Cury AA, Pessanha Henriques GE. Effect of platform connection and abutment material on stress distribution in single anterior implant-supported restorations: a nonlinear 3-dimensional finite element analysis. J Prosthet Dent 2014;112(5):1096-1102

16 Zandparsa R, Albosefi A. An in vitro comparison of fracture load of zirconia custom abutments with internal connection and different angulations and thicknesses: part II. J Prosthodont 2016;25(2):151-155

17 Behnaz E, Ramin M, Abbasi S, Pouya MA, Mahmood F. The effect of implant angulation and splinting on stress distribution in implant body and supporting bone: A finite element analysis. Eur J Dent 2015;9(3):311-318

18 Mohammed HH, Lee JH, Bae JM, Cho HW. Effect of abutment screw length and cyclic loading on removal torque in external and internal hex implants. J Adv Prosthodont 2016;8(1):62-69

19 Cerutti-Kopplin D, Rodrigues Neto DJ, Lins do Valle A, Pereira JR. Influence of reverse torque values in abutments with or without internal hexagon indexes. J Prosthet Dent 2014;112(4):824-827

20 Gil FJ, Herrero-Climent M, Lázaro P, Rios JV. Implant-abutment connections: influence of the design on the microgap and their fatigue and fracture behavior of dental implants. J Mater Sci Mater Med 2014;25(7):1825-1830 
21 Geng JP, Tan KB, Liu GR. Application of finite element analysis in implant dentistry: a review of the literature. J Prosthet Dent 2001;85(6):585-598

22 Fabbri G, Fradeani M, Dellificorelli G. De Lorenzi M, Zarone F, Sorrentino R. Clinical evaluation of the influence of connection type and restoration height on the reliability of zirconia abutments: a retrospective study on 965 abutments with a mean 6-year follow-up. Int J Periodontics Restorative Dent 2017;37(1):19-31

23 Baldassarri M, Hjerppe J, Romeo D, Fickl S, Thompson VP, Stappert CF. Marginal accuracy of three implant-ceramic abutment configurations. Int J Oral Maxillofac Implants 2012;27(3):537-543

24 Pinheiro Tannure AL, Cunha AG, Borges Junior LA, da Silva Concílio LR, Claro Neves AC. Wear at the implant-abutment interface of zirconia abutments manufactured by three CAD/CAM systems. Int J Oral Maxillofac Implants 2017;32(6):1241-1250

25 de Araújo GM, de França DG, Silva Neto JP, Barbosa GA. Passivity of conventional and CAD/CAM fabricated implant frameworks. Braz Dent J 2015;26(3):277-283

26 Pereira LMS, Sordi MB, Magini RS. Calazans Duarte AR, M Souza JC. Abutment misfit in implant-supported prostheses manufactured by casting technique: an integrative review. Eur J Dent 2017;11(4):553-558
27 Alsahhaf A, Spies BC, Vach K, Kohal RJ. Fracture resistance of zirconia-based implant abutments after artificial long-term aging. J Mech Behav Biomed Mater 2017;66:224-232

28 Dhingra A, Weiner S, Luke AC, Ricci JL. Analysis of dimensional changes in the screw and the surface topography at the interface of a titanium screw and a zirconia abutment under cyclic loading: an in vitro study. Int J Oral Maxillofac Implants 2013;28(3):661-669

29 Elsayed A, Wille S, Al-Akhali M. Kern M. Effect of fatigue loading on the fracture strength and failure mode of lithium disilicate and zirconia implant abutments. Clin Oral Implants Res 2018;29(1):20-27

30 Sailer I, Asgeirsson AG, Thoma DS, et al. Fracture strength of zirconia implant abutments on narrow diameter implants with internal and external implant abutment connections: A study on the titanium resin base concept. Clin Oral Implants Res 2018;29(4):411-423

31 Cavusoglu Y, Akça K, Gürbüz R, Cehreli MC. A pilot study of joint stability at the zirconium or titanium abutment/ titanium implant interface. Int J Oral Maxillofac Implants 2014;29(2):338-343 